\title{
Internacionalización de la educación superior: Una exploración introductoria acerca de su presencia en las carreras de posgrado de la Universidad de Costa Rica
}

\author{
Internationalization of the higher education. An introductory exploration about its \\ presence in the posgraduate programs of the University of Costa Rica
}

\author{
Luis Muñoz Varela ${ }^{1}$ \\ Universidad de Costa Rica \\ Instituto de Investigación en Educación \\ San José, Costa Rica \\ LUIS.MUNOZ@ucr.ac.cr \\ ORCID: http://orcid.org/0000-0003-0937-0860
}

\begin{abstract}
Recibido: 5 diciembre 2014 Aceptado: 22 octubre 2015 Corregido: 14 marzo 2016
\end{abstract}
\begin{abstract}
Resumen: Este artículo tiene por finalidad presentar los resultados de una investigación realizada en torno a la información que ofrecen los programas y carreras de posgrado de la Universidad de Costa Rica (UCR), respecto de la gestión y diversas acciones académicas que se llevan a cabo en materia de internacionalización de la educación superior. La investigación se hizo mediante una revisión de la información contenida en páginas web e incluyó la consideración de aspectos tales como: a) incorporación de contenidos de internacionalización en los planes de estudio; b) disponibilidad de páginas web propias; c) divulgación de las líneas de investigación en las que se trabaja en los programas y carreras; d) relaciones de cooperación con universidades, centros e institutos de investigación, agencias de cooperación y organismos internacionales; e) dominio de una segunda lengua como requisito de ingreso a los programas y carreras. Se concluye que, hasta el presente, la internacionalización no parece haber sido todavía una cuestión que haya llegado a tener mayor presencia en las actividades de gestión y de divulgación de información que se llevan a cabo en los programas y las carreras de posgrado de la UCR.
\end{abstract}

Palabras clave: Internacionalización de la educación superior, programas y carreras de posgrado, Universidad de Costa Rica, intercambio académico, movilidad académica, gestión de la educación superior.

\begin{abstract}
This article aims to show the results of a research about the information provided in postgraduate programs and study plans at the University of Costa Rica (UCR), related to various academic and management actions performed dealing with the internationalization process of
\end{abstract}

1 Licenciado en Filosofía (Escuela de Filosofía de la Universidad de Costa Rica). Maestro en Ciencias en Investigaciones Educativas (Departamento de Investigaciones Educativas del CINVESTAV, México). Integrante del equipo de investigación del "Observatorio de la Educación Nacional y Regional" del Instituto de Investigación en Educación (INIE), Universidad de Costa Rica. Coordinador del proyecto "Observatorio sobre Movilidades Académicas y Científicas en Costa Rica" (OBNAT), adscrito al programa de investigación "Observatorio de la Educación Nacional y Regional" del INIE/UCR y al Observatorio sobre Movilidades Académicas y Científicas (OBSMAC) del Instituto Internacional para la Educación Superior en América Latina y el Caribe (IESALC) de la UNESCO. Publicaciones recientes: Muñoz Varela, Luis. (2014). Autonomía universitaria hoy: Una reflexión necesaria. Revista de Ciencias Sociales, núm. 144 (2014). Muñoz Varela, Luis. (2014). Comunidad investigadora de la Universidad de Costa Rica. Una aproximación exploratoria y descriptiva. Revista Actualidades Investigativas en Educación, vol. 14, núm. 2 (2014). 
higher education. The research was done by reviewing the information on Web pages and included considering aspects such as: a) inclusion of content in the curricula related to internationalization; b) availability of own Web pages; c) dissemination of the research work under study; d) partnerships with universities, investigation institutes, cooperation agencies and international organizations; e) mastery of a second language as a requirement for admission to programs and plans. It concludes that, to date, internationalization does not seem to have had a greater significance in the activities of management and information disclosure conducting programs and postgraduate courses at UCR.

Keywords: Internationalization of the higher education, postgraduate programs, University of Costa Rica, academic exchange, academic mobility, management of the higher education.

\section{Introducción}

La internacionalización es un tema que desde hace ya más de dos décadas ha tomado un lugar de importancia en la investigación especializada, lo mismo que en los discursos institucionales sobre la educación superior (Muñoz, 2014). En su abordaje y formulaciones entran en consideración los más diversos aspectos del quehacer académico e institucional de la universidad, por cuanto se plantean también distintas modalidades o énfasis en los que puede ponerse de manifiesto el desarrollo de acciones de internacionalización en la universidad, según sean las especificidades que caracterizan a cada institución y según las concretas identidades y contextos institucionales, culturales y nacionales en los que cada una de ellas está inscrita y desarrolla sus actividades.

En la Universidad de Costa Rica (UCR), puede decirse que, hasta el presente, el tema de la internacionalización no parece haber adquirido todavía mayor interés ni una expresión significativa en las preocupaciones y las iniciativas de investigación por parte de la comunidad universitaria, como tampoco, en su caso específico, para las instancias de gestión de los programas y las carreras de posgrado. Esto es así, aun cuando, por otra parte, también es posible observar que de diversa manera ha habido variadas actividades académicas y de gestión en las que se manifiestan acciones de internacionalización, asumidas estas como expresión natural del quehacer que le es propio a la universidad. La internacionalización es, en efecto, un componente natural del quehacer académico y de la gestión institucional en la universidad.

En 2011, el Consejo Nacional de Rectores (CONARE), entidad que agrupa a las 5 universidades estatales del país, incluyó el siguiente señalamiento, como uno de los objetivos del Plan Nacional de la Educación Superior Universitaria Estatal 2011/2015:

1.5.1. Fortalecer las acciones del sistema interuniversitario estatal en materia de internacionalización, entendiendo que ésta es un factor fundamental para la calidad académica, la promoción de la investigación y el aporte a la sociedad. (Consejo Nacional de Rectores, 2011, p. 90)

En este objetivo puede decirse que queda esbozada la visión general que las universidades estatales de Costa Rica tienen en relación con la internacionalización de la educación superior. Indica además cuáles son los ámbitos de quehacer académico en los que se debe hacer 
énfasis, así como subraya que esa internacionalización ha de constituir un aporte a la sociedad desde la universidad.

Desde una perspectiva de la educación superior entendida como bien público, la anterior visión toma en cuenta los diferentes aspectos del intercambio de los conocimientos, la cooperación internacional, la movilidad docente y estudiantil, los proyectos académicos conjuntos con universidades del exterior, los programas de becas, la flexibilización de los programas para la internacionalización del currículo, la oferta de estudios para estudiantes extranjeros, así como desarrollar "actividades para mejorar la capacidad académica en un segundo idioma, en particular el idioma inglés, en los profesores, estudiantes y funcionarios universitarios" (Consejo Nacional de Rectores, 2011, p. 90).

Este artículo tiene por finalidad presentar los resultados de una indagación exploratoria realizada acerca de la internacionalización del posgrado en la UCR, que se llevó a cabo por medio de una revisión pormenorizada de la información accesible y exhibida en la página web del Sistema de Estudios de Posgrado (SEP). La exploración emprendida se propuso como una primera fase de una acción de investigación más amplia, que en un segundo momento involucrará aplicar una encuesta a las personas que tienen a su cargo la dirección de cada uno de los diferentes programas y carreras de posgrado de la UCR. En este sentido, los resultados que aquí se presentan deben ser entendidos en términos de una aproximación preliminar al estudio de la cuestión.

\section{Referencialidad teórica}

\section{II.1. Especificidades de contexto estructural}

Con la instauración como nueva realidad estructural e institucional de la globalización y la economía basada en el conocimiento (Proyecto Estrategia Siglo XXI, 2006), el tema de la internacionalización de la educación superior pasó a ser una cuestión presente cada vez más en la discusión y en el análisis en torno a las diferentes funciones, finalidades, actividades académicas y tareas de gestión que se llevan a cabo en las universidades (de Wit, 2011).

De un quehacer institucional y académico que otrora se anclaba de manera predominante en las territorialidades locales y que respondía a los requerimientos del Estado/Nación, la difuminación de las fronteras nacionales resultante de la emergencia de un mundo interconectado planetariamente, vino a plantear nuevas condiciones, demandas y desafíos para los sistemas de educación superior y para cada una de las universidades. Según dice Moja (2009): "Los sistemas de educación superior, inicialmente creados para cubrir las necesidades de los estados nacionales, se enfrentan ahora al desafío de abordar necesidades que van más allá de este marco" (p. 42).

Ya en 1998, la Conferencia Mundial sobre la Educación Superior (CMES 98) de la UNESCO declaraba que "la educación superior ya no se puede concebir solamente a partir de situaciones y criterios nacionales. Ya no existe investigación o formación dignas de ese nombre en términos puramente locales" (Conferencia Mundial sobre la Educación Superior, 1998, p. 12). Esta nueva situación emergente, en la CMES 98 quedó conceptuada en términos de "mundialización". 
El mundo en el que nos toca vivir es ya un mundo global en el que todo está relacionado, tanto nacional como internacionalmente; un mundo donde las dimensiones financieras, culturales, políticas, ambientales, científicas, etc., son interdependientes, y donde ninguno de tales aspectos puede ser adecuadamente comprendido al margen de los demás. (Torres-Santomé, 2000, p. 31)

La CMES 98 hizo énfasis en el hecho de que, con la globalización y la economía basada en el conocimiento, quedaba abierto un nuevo escenario mundial en el que los grandes problemas de la humanidad pasaban ahora a exigir esfuerzos y acciones conjuntas a escala interinstitucional e internacional. Se entendía, a la vez, que en su caso, la mundialización no hacía referencia "únicamente a la economía", sino que era también "la internacionalización de los intercambios humanos y de la circulación de las ideas" (Conferencia Mundial sobre la Educación Superior, 1998, p. 12).

La globalización es un acontecimiento multidimensional:

La globalización es el flujo de tecnología, economía, conocimientos, personas, valores, ideas... a través de las fronteras. Afecta a cada país de manera diferente en virtud de la historia, las tradiciones, la cultura y las prioridades de cada nación. (Knight, citada por Guido y Guzmán, 2012, p. 4)

No obstante, al unísono que se intensifican los intercambios humanos y la circulación de las ideas, también acontece que la globalización y la economía basada en el conocimiento allegan una profundización de las desigualdades entre las naciones, lo mismo que al interior de las propias sociedades en los diferentes países. "Los procesos globalizadores incluyen una segregación, separación y marginación social progresiva” (Bauman, 2001, p. 9).

En el contexto de la globalización acontecen profundas transformaciones en el sistema económico mundial y en las economías locales nacionales, que tienden a profundizar las desigualdades en los intercambios económicos internacionales y también al interior de la estructura de las relaciones de clase social a escala nacional de cada país.

La exclusión de los países menos desarrollados, en todas las regiones del mundo, es prácticamente absoluta. La exclusión de los países y las personas pobres se extiende más allá del comercio, la inversión y las finanzas, en la medida en que su acceso a la globalización está muy limitado en términos de comunicación y tecnología. (Nayyar, 2009, p. 27)

En un contexto tal, a escala del papel que las instituciones de educación superior están llamadas a asumir y desempeñar, la CMES 98 propuso promover, ampliar y fortalecer la cooperación internacional, el intercambio de los conocimientos y el aprovechamiento de las oportunidades que las nuevas tecnologías pueden favorecer para incidir en las disparidades existentes y para diseñar estrategias que permitan atenderlas y que conduzcan a reducirlas. (Conferencia Mundial sobre la Educación Superior, 1998, p. 20). Las acciones y esfuerzos 
debían dirigirse, entre otras cosas, a buscar la reducción de las desigualdades que afectan de manera especial a los países en desarrollo, a las naciones más pobres y que repercuten en sociedades cada vez más desiguales y fragmentadas.

En consecuencia, la CMES 98 planteó la necesidad de un concepto amplio y complejo de cooperación internacional, que incluyera no solo las relaciones entre las instituciones de educación superior, sino que además procurara ser adoptado también por las diferentes agencias y organismos internacionales y multilaterales de cooperación para el desarrollo y, de manera especial, por aquellas instituciones que se encuentran enfocadas en la cooperación para la educación.

Con todo, en el momento mismo que la CMES 98 formulaba las indicadas propuestas, por otra parte, conforme se intensificaron los procesos estructurales de la globalización económica, también emergieron nuevas tendencias que plantearon la cuestión de la educación superior en términos de mercado y de comercialización transfronteriza de los servicios educativos: "enseñanza sin fronteras", "a través de las fronteras", "enseñanza global", "comercio internacional en los servicios de enseñanza" (JDias, 2008, p. 318; de Wit, 2011, p. 79); instalación en los países de filiales de universidades extranjeras, oferta de titulaciones en línea, universidades corporativas...

Del mismo modo que la globalización ha tendido a hacer que se concentren la riqueza, el saber y el poder en manos de quienes ya los poseían, la movilidad académica internacional ha favorecido a sistemas e instituciones educativos ya desarrollados. Hay claras muestras de desigualdad en el mundo en expansión de la educación superior internacional. (Altbach y Knight, 2006, p. 15)

Las anteriores constituyen dinámicas en las que toma centralidad la competitividad comercial por la captación de estudiantes y docentes y que son desarrolladas por "proveedores internacionales de enseñanza superior con fines de lucro..." (de Wit, 2011, p. 81). Esta situación se encuentra, a su vez, estrechamente asociada con las directrices expresadas por la Organización Mundial del Comercio (OMC), que propugnan por instituir la transformación de la educación superior -y la educación en general- de un bien concebido como de naturaleza pública a un bien más de mercado. Todo ello ha venido a repercutir de una u otra manera y en diversos grados en las instituciones de educación superior, sea cual sea su condición institucional (pública, privada) y su naturaleza académica.

A criterio de M. A. Dias (2008), las fuerzas del mercado globalizado demandan a las universidades:

...reformas, transformaciones, alteraciones, adecuaciones y cambios de paradigmas coherentes con el modelo empresarial modernizante, para que así la educación superior efectivamente cumpla sus nuevos papeles frente a las exigencias de la globalización económica y de la llamada "sociedad del conocimiento y de la información". (p. 97)

A tal efecto, cabe destacar que la CMES 98 planteó la necesidad de fortalecer la cooperación internacional, desde una perspectiva de internacionalización colaborativa y solidaria, "necesaria 
no solamente para fortalecer la calidad, la pertinencia y la eficacia interna de la educación superior, sino también para tender puentes entre los asociados locales y nacionales y entre las naciones" (Conferencia Mundial sobre la Educación Superior, 1998, p. 16).

El principio de solidaridad y de una auténtica asociación entre los establecimientos de enseñanza superior de todo el mundo es fundamental para que la educación y la formación en todos los ámbitos ayuden a entender mejor los problemas mundiales... (Conferencia Mundial sobre la Educación Superior, 1998, p. 29)

En la óptica de la Conferencia, la cooperación internacional, asimismo, no quedaba referida únicamente a las relaciones internacionales de cooperación horizontal, recíproca y solidaria que se pudieran establecer entre las instituciones de educación superior de distintos países y regiones del mundo. Además de esta dimensión fundamental, se promovía también que dicha cooperación se situara en el plano de una articulación internacional que asegurara e hiciera valer la visión de una educación superior al servicio de la búsqueda y el logro de mejores condiciones de vida para las sociedades nacionales de las diferentes naciones, lo mismo que a escala planetaria. De esta manera, la CMES 98 propuso que la educación superior "comprendiera entre sus misiones principales la cooperación internacional y la necesidad de promover la pluralidad de las culturas, una conciencia mundial de los problemas y un desarrollo durable en todo el mundo" (Conferencia Mundial sobre la Educación Superior, 1998, p. 16).

Esta misma visión y heurística de la cooperación internacional y de las relaciones interinstitucionales a escala internacional de la educación superior, también quedó una década después ratificada en el marco de la Conferencia Mundial sobre la Educación Superior de 2009 (CMES 2009):

Las iniciativas conjuntas de investigación y los intercambios de alumnos y personal docente promueven la cooperación internacional. Los estímulos para lograr una movilidad académica más amplia y equilibrada deberían incorporarse a los mecanismos que garantizan una auténtica colaboración multilateral y multicultural. (Conferencia Mundial sobre la Educación Superior, 2009, p. 5)

Un año antes de la CMES 2009, en 2008, la Conferencia Regional de Educación Superior en América Latina y el Caribe (CRES 2008), por su parte, ya enunciaba lo siguiente:

Propugnar la integración regional latinoamericana y caribeña y la internacionalización de la educación superior en la región mediante, entre otras iniciativas, la construcción del ENLACES -Espacio de Encuentro Latinoamericano y Caribeño de Educación Superior- y la cooperación sur-sur y norte-sur sur. (González, 2010, p. 35)

\section{II.2. Internacionalización}

En el contexto de la globalización y de la economía basada en el conocimiento, durante las últimas dos décadas, la internacionalización de la educación superior se ha ampliado en 
"volumen, alcance y complejidad" (Altbach y Knight, 2006, p. 14). Además de los programas tradicionales de estudios en el extranjero, han aparecido ahora otras expresiones de internacionalización:

...instalación de campus satélite en otros países, las franquicias de programas o grados académicos extranjeros, la creación de instituciones independientes basadas en modelos académicos extranjeros en países específicos y otros modelos. Otros enfoques ponen el énfasis en un mejoramiento de la visión internacionalista y de las capacidades de los estudiantes en el campus, apoyando los programas de lenguas extranjeras y abriendo espacios para el diálogo transcultural. (Altbach y Knight, 2006, p. 14)

Como factores de la internacionalización de la educación superior, la bibliografía especializada destaca los siguientes:

La tecnología de la información, la economía del conocimiento, la movilidad cada vez mayor de los estudiantes, profesores, programas y proveedores y la integración creciente de la economía mundial son factores que estimulan esta internacionalización. Sin duda, la tendencia a la internacionalización seguirá siendo una fuerza central en la educación superior para el futuro inmediato. (Altbach y Knight, 2006, p. 36)

"La internacionalización de la educación superior es una de las maneras en que un país responde a las repercusiones de la globalización, no obstante que respeta la idiosincrasia de la nación" (Knight, s. f., p. 1). Sin embargo, durante los últimos años, la internacionalización también se ha desarrollado de manera tendencial inscrita en una perspectiva de mercado y de competitividad comercial, que pone en riesgo la posibilidad de mantener las propias idiosincrasias e identidades nacionales e institucionales; "las funciones de la universidad están cada vez más condicionadas a las fuerzas del mercado" (Altbach, 2009, p. 34). "En el mundo de la educación superior, los mercados y la globalización están empezando a influir en las universidades y a modelar la educación no sólo en términos de lo que se enseña, sino también en términos de lo que se investiga" (Nayyar, 2009, p. 29).

De esa manera, las dinámicas de mercado y de comercialización han abierto las condiciones y los espacios para que, similar a como acontece con las economías, se diluyan las fronteras nacionales y que la disposición y la oferta de los servicios de la educación superior se transnacionalice y se convierta en una actividad económica más de carácter privado y lucrativo.

La competencia creciente en la enseñanza superior y la comercialización y el suministro transfronterizo de enseñanza superior han desafiado el valor tradicionalmente atribuido a la cooperación, como los intercambios y las asociaciones. (de Wit, 2011, p. 78)

En tal sentido, las lógicas y dinámicas de la globalización económica penetran también en las configuraciones de política institucional y de actuación programática de la educación superior, orillando a estas instituciones a incorporar las pautas de la competitividad mercantil. 
Una de las tendencias que ha tomado auge en el marco de la internacionalización basada en la competitividad de mercado y en la transnacionalización mercantil de los servicios de educación superior es la del posicionamiento publicitario de las universidades por la vía de las estrategias de la mercadotecnia, una de ellas la del emergente paradigma de los "rankings" mundiales de universidades.

Debe reconocerse que, en la actual era de la globalización y de la interconexión planetaria, la divulgación de la labor académica que se realiza en la universidad pasa a tener una importancia especial, sobre todo a propósito de establecer relaciones de intercambio y colaboración con universidades localizadas en diferentes países y regiones del mundo. Sin embargo, una cosa es la divulgación de información que se hace con tales finalidades y otra bien distinta la que se encuentra implicada en las estrategias de la mercadotecnia.

Si bien es cierto que en la actualidad aparecen diversas propuestas acerca de cómo dar mayor visibilidad y proyección internacional al quehacer académico de las universidades, también es necesario tener en cuenta que las iniciativas y acciones que se desarrollen en tal sentido, no debieran comprometer la naturaleza académica del quehacer universitario ni, todavía menos, abrir la posibilidad de que se distorsione el principio de la autonomía universitaria, al facilitar condiciones desde la universidad para que la propia política académica y de gestión institucional pase a ser determinada por la adopción e instauración de directrices externas, surgidas en otras regiones del mundo y en el contexto de tendencias que difieren y riñen con los principios fundamentales de la universidad pública en un país como Costa Rica.

La mercadotecnia incorporada a la gestión en la universidad está asociada con campañas publicitarias a escala de la competitividad comercial, para granjearse un nombre y prestigio que favorezcan la obtención de ingresos por la vía del incremento de la matrícula (Altbach y Knight, 2006). En el fondo, tácitamente esto es lo que anima y motiva la aparición de ciertas iniciativas institucionales, tales como la de otorgar premios a la comunidad universitaria emprendedora, o bien, incluso, aquellas que declaran moratorias para la creación de nuevas revistas en la universidad, argumentándose para ello la necesidad de fortalecer primero la calidad y la competitividad internacional de las ya existentes.

En una acepción genuinamente universitaria, la divulgación no debiera despojarse de su naturaleza académica, ni reducirse a una cuestión de aplicar determinados indicadores de la gerencia comercial de la comunicación y la información. La organización administrativa y técnica de la divulgación es tan solo un aspecto de lo que esa labor implica, que debe estar asociada y coordinada con una visión política y pedagógica precisa y clara sobre el significado que el quehacer académico de la educación superior tiene para los procesos del desarrollo nacional, basados en los principios de la democracia, la equidad, la justicia y la solidaridad social, la inclusión y la mejora de las condiciones de vida en general para toda la sociedad en su conjunto.

En tal sentido, a diferencia de las tendencias de mercado y de competitividad comercial, la perspectiva de la internacionalización de la educación superior puede ser concebida y asumida como una opción por medio de la cual las universidades "pueden ayudar a resistir a la globalización corporativa global ofreciendo un tipo alternativo de cultura que sea más afín a la cultura pública global" (Delanty, 2009, p. 60). En la actualidad, es necesario que las instituciones universitarias "aborden cuestiones globales y se centren en una agenda basada en el desarrollo humano y social” (Moja, 2009, p. 42). 
Para colaborar con la construcción de un mundo mejor, la educación internacional tendría que estar presente en todas las actividades de formación y de investigación de la educación superior: intercambios de profesores, investigadores y estudiantes, programas compartidos de investigación y de formación, intercambio de información, publicaciones conjuntas, etc. (MADias, 2008, p. 359)

La investigación conjunta es necesaria para consolidar un marco conceptual, explorar nuevos métodos analíticos y sondear nuevas formas de conocimiento, pensamiento, actuación, así como adaptación de los propios valores. Asimismo, sería muy conveniente la búsqueda de herramientas para la comprensión de la multiculturalidad y de los valores comunes, muy numerosos, que permitan obtener beneficios de una diversidad enriquecedora, así como promover la convivencia y la paz. (Bennani, 2009, p. 59)

Las acciones de internacionalización en la universidad pueden orientarse en distintos sentidos: allegar perspectivas de interés para el desarrollo de la reforma curricular y la mejora de la pertinencia de las carreras; actualización de los planes de estudio; diversificación de los intercambios académicos en docencia e investigación; acceso a los conocimientos y a las redes universitarias, regionales y extra regionales; impulsar experiencias de formación compartidas que favorezcan la movilidad y la pedagogía de la interculturalidad; la mejora de las propias condiciones de excelencia académica en comparación con programas similares que se imparten en universidades de otros países y regiones del mundo (Knight, 2011).

La internacionalización, en consecuencia, viene a ser una opción que puede permitir a las universidades organizar mejor sus relaciones interinstitucionales internacionales, tanto a escala de programas (servicios educativos, de investigación y universitarios) como de estrategias organizacionales (los sistemas operativos y de gestión).

Una perspectiva común y tradicional de la internacionalización de la educación superior sitúa a esta en los planes de estudio y en la movilidad académica y de estudiantes para realizar estudios en el exterior (de Wit, 2011). Colocada en la actualidad, dicha orientación indicaría que de lo que se trata es de realizar adecuaciones en los planes de estudio que lleven a incorporar contenidos tales como el de la interculturalidad y, también, el aprendizaje de un segundo idioma. Se encuentra contenida en esta indicación la preocupación por facilitar una formación que contribuya a desarrollar la conciencia de las actuales condiciones de la vida humana en un mundo interconectado a escala planetaria, para las cuales las nuevas generaciones deben estar preparadas para interactuar y desenvolverse en ellas de la manera más apropiada posible. Knight (2005) indica que a esa orientación de la internacionalización se la denomina como "internacionalización en casa" (p. 10).

Internacionalización en casa trata de establecer un vínculo más estrecho entre los conceptos de internacional e intercultural en el campo de la educación; representa una etapa importante en el desarrollo de la dimensión internacional e intercultural en la educación. (p. 10) 
La "internacionalización en casa" se propone como una alternativa que puede ser de interés de manera especial para aquellos países donde los costos de traslado de sus estudiantes al extranjero pueden constituirse en una limitación importante para el desarrollo de la movilidad estudiantil.

El foco principal de las IES es la preparación de los estudiantes para un mundo globalizado. Al mismo tiempo, se ha evidenciado que este objetivo no se alcanzará mediante la movilidad hacia fuera tradicional, que continuará siendo una herramienta para una pequeña minoría de estudiantes. Sólo el plan de estudios puede proporcionar al graduado las competencias interculturales e internacionales necesarias. Por lo tanto, hay que clarificar cuál es el papel del plan de estudios como herramienta para conseguirlo. (Beelen, 2011, p. 98)

En la UCR, la tendencia pareciera orientarse por la incorporación de un segundo idioma en las carreras y por la flexibilización de los planes de estudio, con el desarrollo de "cursos, proyectos compartidos y conferencias en línea, todo en inglés" (Ocampo, 2014, párr. 3). Esta orientación es la que ha empezado a promover la Red Institucional de Formación y Evaluación Docente (RIFED) y que incluye la participación y el intercambio docente con universidades del extranjero para impartir cursos y dar videoconferencias. Se indica que la incorporación del inglés como segundo idioma se debe a la proximidad geográfica que tiene Costa Rica con Estados Unidos.

\section{II.3. Internacionalización del posgrado}

Las acciones de internacionalización requieren hoy ser organizadas en políticas institucionales integradas. La iniciativa individual siempre resulta de gran valor, pero no puede dejarse a su propia suerte, sin que reciba o no se le proporcione el apoyo institucional adecuado. Es muy importante, por consiguiente, que exista definida en la universidad una política institucional de internacionalización, cuya formulación y establecimiento sea, además, producto de un amplio y diverso proceso de consulta con las diferentes unidades académicas y los diferentes sectores que conforman la comunidad universitaria.

La experta canadiense J. Knight (2005) refiere cuatro distintas estrategias para la internacionalización de la educación superior: a) establecimiento de vínculos internacionales para la creación de programas académicos y desarrollo de proyectos de investigación conjuntos; b) "educación en otros países por medio de nuevos tipos de planes, seccionales de ciudades universitarias o exenciones y el empleo de diversas técnicas cara a cara y a distancia"; c) "inclusión de una dimensión internacional, intercultural o global en el plan de estudios y el proceso de enseñanza/aprendizaje"; d) "proyectos de desarrollo y mayor énfasis en el comercio" (p. 2).

En la UCR, la experiencia institucional de internacionalización del posgrado puede decirse que dio inicio desde un momento en que todavía estaba bastante distante en el tiempo la aparición de la imagen de la internacionalización de la educación superior, según la configuración conceptual y acepciones que pasó a adquirir a partir de la década de 1990 (Beleen, 2011). Dicha experiencia está asociada especialmente con la creación a escala regional centroamericana, a inicios de la década de 1960, del Sistema de Carreras y Posgrado Regionales (SICAR) del Consejo Superior Universitario Centroamericano (CSUCA). 
En la actualidad, las acciones de internacionalización pueden posibilitar a las carreras de posgrado disponer de espacios para desarrollar iniciativas de intercambio en materia de investigación; experiencias y nuevos enfoques curriculares; pertinencia y relevancia de los estudios de posgrado para un desarrollo nacional equitativo, con justicia social, democrático, solidario, incluyente e integral; contribución de las personas tituladas de posgrado en los ámbitos institucionales, económicos, productivos, científicos y de intervención en diferentes campos de actividad; movilidad estudiantil y académica; capacitación para el fortalecimiento de la enseñanza y de los perfiles en general de la planta académica.

\section{Qué se hizo en esta indagación exploratoria}

El presente artículo es resultado de una exploración preliminar realizada en torno a la internacionalización del posgrado en la Universidad de Costa Rica (UCR). En primera instancia, se hizo una búsqueda y revisión de artículos especializados sobre el tema de la internacionalización de la educación superior, publicados en revistas y libros.

La pregunta central que guio la exploración cuyos resultados se presentan aquí fue: ¿Cuál es la incorporación que se ha hecho de contenidos de internacionalización en los planes de estudio de las carreras de posgrado de la UCR, así como en la información que sobre sí mismas esas carreras ofrecen por medio de páginas web?

Para llevar a cabo la indagación exploratoria preliminar, lo que se hizo fue, básicamente, realizar un análisis pormenorizado de la información que aparece registrada en la página web del Sistema de Estudios de Posgrado (SEP) de la UCR, relacionada con los diferentes programas y carreras de posgrado de esta universidad.

La exploración realizada tuvo por finalidad identificar en qué medida existe información relacionada con al menos algunos de los diferentes aspectos que conciernen a las acciones de internacionalización de la educación superior, llevadas a cabo por los programas y las carreras de posgrado de la UCR.

Los indicadores de internacionalización utilizados para orientar y realizar esta investigación son los siguientes: a) incorporación de contenidos de internacionalización en los planes de estudio; b) un segundo idioma como requisito de ingreso; c) relaciones y convenios con universidades del extranjero y la localización geográfica de estas; d) participación en redes internacionales de docencia e investigación; e) gestión para atraer a estudiantes del extranjero a realizar estudios en las carreras de posgrado,f) líneas básicas de investigación.

\section{Resultados}

\section{IV.1. Población estudiantil de pregrado, grado y posgrado en la UCR}

\section{Pregrado y grado}

$\mathrm{Al}$ año 2012, la población estudiantil total de la UCR en las carreras de pregrado y grado era de 37.349 estudiantes (Oficina de Planificación Universitaria, 2012). En su lugar, 
la matrícula total en las carreras de posgrado era de 3.601 estudiantes. Esta cifra representa una proporción comparativa de $9,64 \%$ con respecto a las carreras de pregrado y grado.

En general, para el conjunto de las 5 universidades estatales del país, la información que, para el año 2012 proporciona el Consejo Nacional de Rectores (CONARE), registra una cantidad total de 93,387 estudiantes, distribuida proporcionalmente según se muestra en la figura 1.

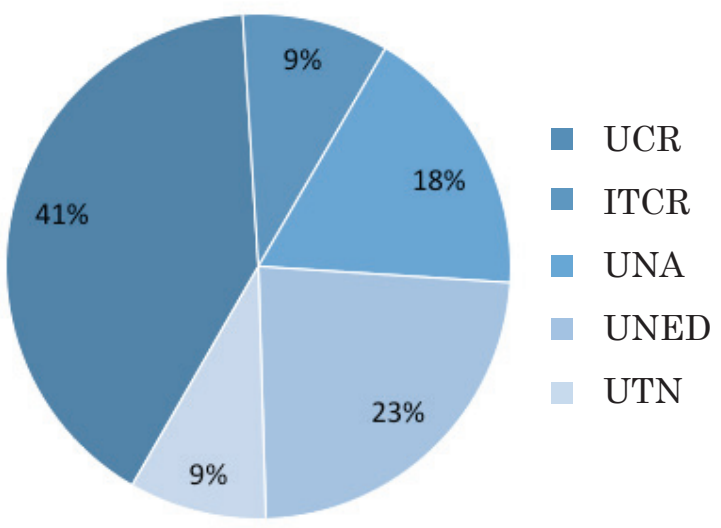

Figura 1. Distribución del total de la matrícula en las universidades estatales, año 2012 Elaboración propia a partir de CONARE, Servicios de información sobre estadísticas de educación superior (2014)

Por su parte, para el mismo año 2012, según informa el Programa Estado de la Nación (2013), la matrícula total registrada para todo el sistema universitario nacional se cifraba en 195.364 estudiantes: " $51,8 \%$ en el sector privado y un $47,6 \%$ en universidades estatales" (p. 197). Esto significa que, para el caso específico de la UCR, esta universidad participa en una relación proporcional de $19,1 \%$ en la matrícula total del sistema universitario nacional, conformado por 5 universidades públicas y 52 entidades de educación superior privadas (p. 202).

\section{IV.2. Carreras de pregrado, grado y posgrado}

\section{Pregrado y grado}

De conformidad con la información que proporciona la Oficina de Planificación Universitaria (OPLAU), en 2012 la UCR contaba con una oferta académica de pregrado y grado constituida por una cantidad total de 244 opciones, distribuidas de la siguiente manera: a) Diplomado: 24; b) Bachillerato: 135; c) Licenciatura: 85. La figura 2 muestra la distribución proporcional de las carreras de pregrado y grado en la UCR para el año 2012. 


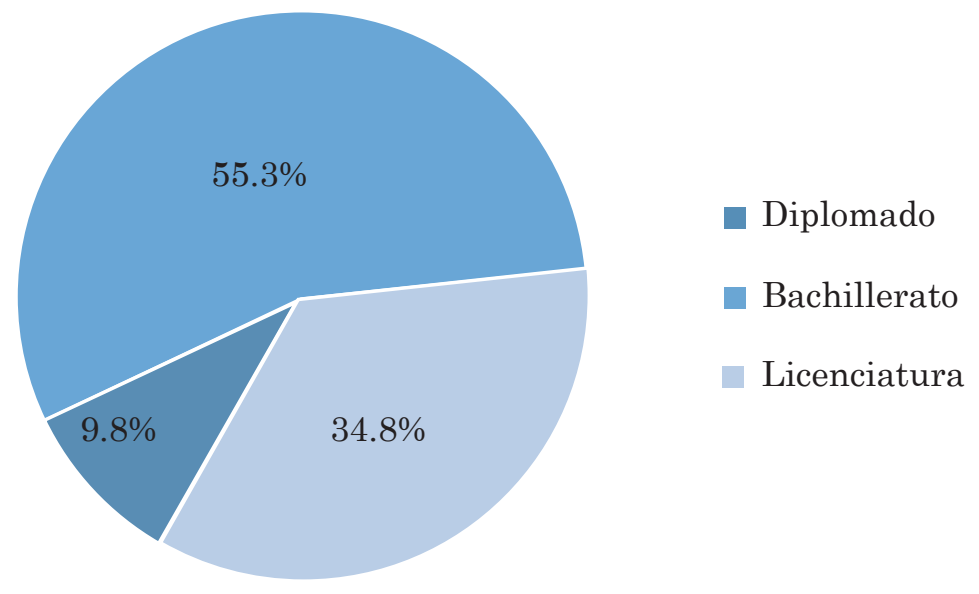

Figura 2. Distribución proporcional de carreras de pregrado y grado en la UCR. Elaboración propia a partir del Panorama cuantitativo universitario 2012, elaborado por la OPLAU, UCR (2014).

\section{Posgrado}

Las carreras de posgrado en la UCR están organizadas en el Sistema de Estudios de Posgrado (SEP). Este sistema inició sus actividades en 1975, con 4 programas en las facultades o escuelas de Microbiología, Filosofía, Ciencias Agrícolas, Química. El SEP es una instancia integrada a la Vicerrectoría de Investigación y se creó desde la perspectiva de constituirse como:

(...) una red de redes que permita la interrelación ágil y efectiva entre los posgrados, con el grado (Escuelas y Facultades), la investigación (Centros e Institutos) e instituciones nacionales o extranjeras, como espacios de colaboración y posibilidad de respuesta efectiva a las necesidades y demandas sociales. (Pérez, s. f., párr. 1)

En la UCR, a partir de entonces, el posgrado se organizó en una conformación por programas. Al año 2014, en el SEP existen 67 programas inscritos, distribuidos proporcionalmente según se muestra en la figura 3. De los 67 programas, 6 poseen un carácter interdisciplinario y se sitúan en las siguientes áreas: Artes y Letras (1), Ciencias Básicas (1), Ciencias Sociales (1), Ingeniería y Arquitectura (1), Salud (2). 


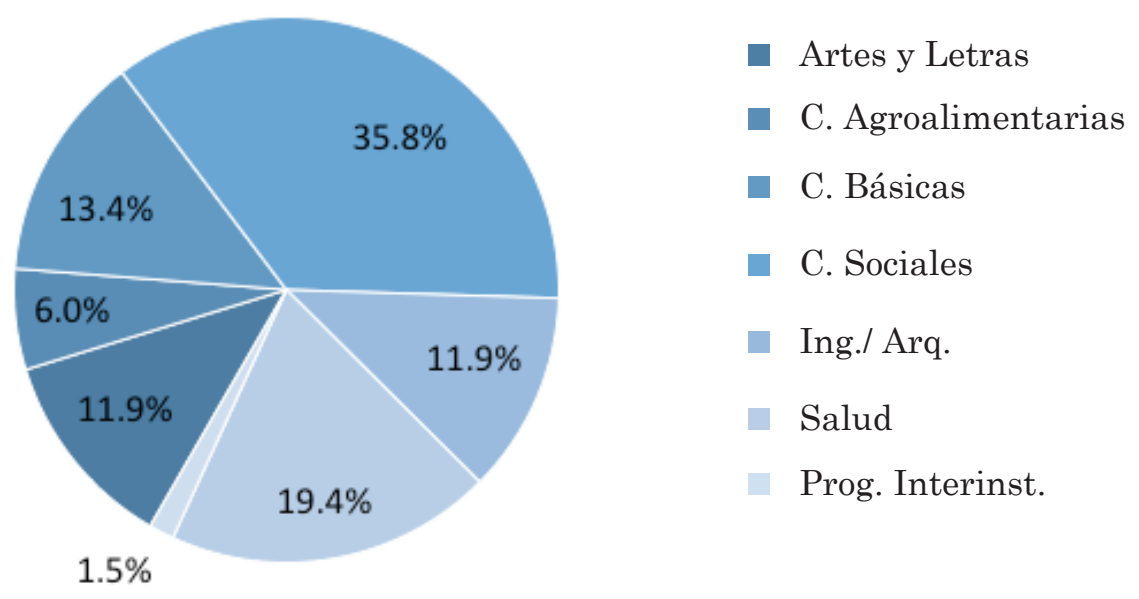

Figura 3. Distribución de programas de posgrado por áreas académicas.

Sistema de Estudios de Posgrado (SEP), Universidad de Costa Rica (2014).

Según se puede observar, el área de Ciencias Sociales es la que concentra la mayor cantidad de programas de posgrado, seguida por las de Ciencias Básicas, Salud y Artes y Letras. En la figura 4 se presenta la distribución de los programas de posgrado, por grados de titulación.

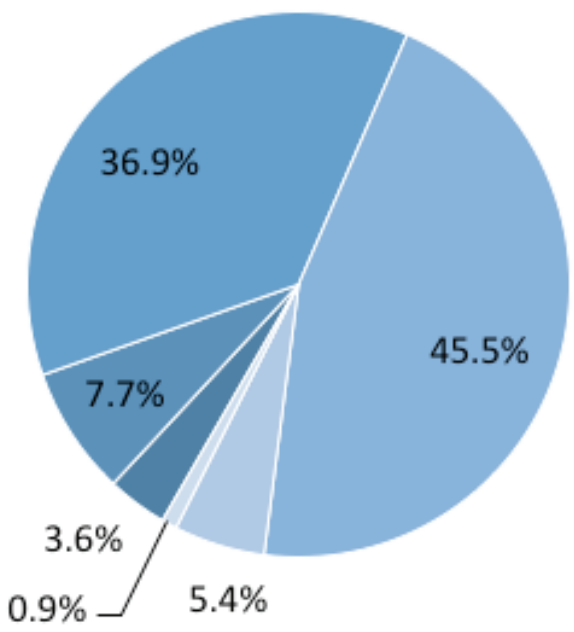

Doctorado

Especialidad

- Maestría académica

Maestría profes.

- Progr. Interdiscipl.

Progr. Insterinst.

Figura 4. Distribución de programas de posgrado por grados de titulación. Sistema de Estudios de Posgrado (SEP), Universidad de Costa Rica (2014). 
Los programas de posgrado están a su vez constituidos por una o varias carreras, cada una de ellas con su respectivo plan de estudios. En la actualidad, la cantidad total de carreras de posgrado registradas en el SEP es de 220 y su distribución por áreas académicas es como se presenta en la figura 5.

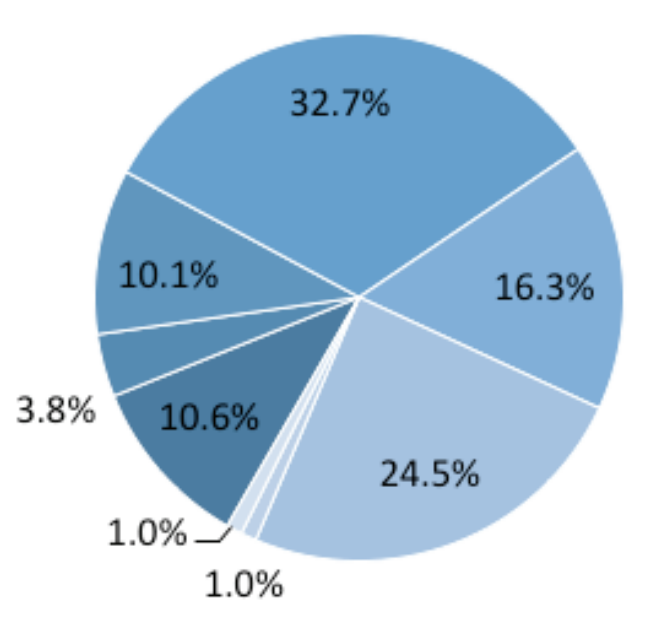

Figura 5. Distribución de carreras de posgrado por áreas académicas. Sistema de Estudios de Posgrado (SEP), Universidad de Costa Rica (2014).

Tal como puede observarse al hacer una comparación proporcional entre las figuras 3 y 5, en la distribución por programas y la distribución por carreras se presentan algunas pequeñas diferencias por áreas académicas. Así, en la distribución por carreras disminuyen levemente su participación las áreas de Artes y Letras (-1,3\%), Ciencias Agroalimentarias $(-2,2 \%)$, Ciencias Básicas $(-3,3 \%)$ y Ciencias Sociales (-3,1\%), mientras que incrementan su participación las áreas de Ingeniería y Arquitectura $(+4,4 \%)$ y de Salud $(+5,1 \%)$.

Es pertinente mencionar, asimismo, que al hacer una comparación de la información disponible en la página web del SEP, esta difiere en relación con la que por su parte presenta la Oficina de Planificación Universitaria (OPLAU) de la UCR. Según el registro que ofrece la OPLAU, en el documento Panorama cuantitativo universitario 2012, en la UCR existirían 243 carreras de posgrado; es decir, 23 más de las que actualmente aparecen registradas en la página web del SEP.

Otro dato que resulta finalmente de interés mencionar aquí es el de la comparación de la cantidad de carreras de posgrado de la UCR, en relación con las otras 3 universidades estatales del país que también cuentan con una oferta de titulación de posgrado: ITCR, UNA y UNED. Según la información que aparece en las correspondientes páginas web de esas instituciones, el ITCR cuenta con 14 carreras de posgrado, la UNA tiene 51 y la UNED 26. La distribución porcentual de las carreras de posgrado de estas instituciones presenta en la figura 6 


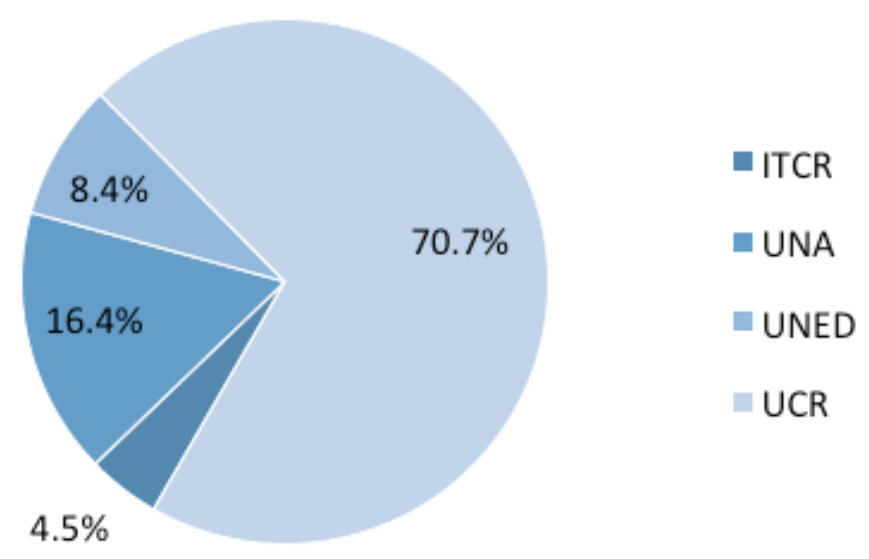

Figura 6. Distribución de carreras de posgrado por universidades estatales. Información tomada de las páginas web de ITCR (2014) UNA (2014) y UNED (2014).

\section{IV.3. Distribución de las categorías de titulación de posgrado por áreas académicas}

Los diferentes grados de titulación de posgrado existentes en la UCR (doctorado, maestría académica, maestría profesional y especialidad) se distribuyen por áreas académicas de la siguiente manera:

Doctorado: a) Artes y Letras: 1; b) Ciencias Agroalimentarias: 1; c) Ciencias Básicas: 1 (programa interdisciplinario; d) Ciencias Sociales: 6(incluye un programa interdisciplinario); e) Ingenierías: 1. El área de Salud no registra con una titulación de doctorado.

Maestría académica: En total, existen en la UCR 84 titulaciones de posgrado en la categoría de "maestría académica", distribuidas por áreas académicas de la siguiente manera: a) Artes y Letras: 14 (16,66\%); b) Ciencias Agroalimentarias: 5 (5,95\%); c) Ciencias Básicas: 15 (17,85\%); d) Ciencias Sociales: 18 (21,42\%); e) Ingeniería: 9 (10,71\%); f) Programas Interdisciplinarios: 4 (4,76\%); g) Programas Interinstitucionales: 1 (1,19\%); h) Salud: 18 (21,42\%). Según se puede apreciar, las áreas académicas que registran una mayor proporción de maestrías académicas son: a) Ciencias Sociales, b) Salud y c) Ciencias Básicas.

Maestría profesional: Las titulaciones de posgrado en la categoría de "maestría profesional" suman en total 95 (11 más que las de "maestría académica"), distribuidas por áreas académicas como sigue: a) Artes y Letras: 6 (6,31\%); b) Ciencias Agroalimentarias: 2 (2,10\%); c) Ciencias Básicas: 4 (4,21\%); d) Ciencias Sociales: 41 (43,15\%); e) Ingenierías: 19 (20\%); f) Programas Interdisciplinarios: 6 (6,31\%); g) Programas Interinstitucionales: $1(1,05 \%)$; h) Salud: $16(16,84 \%)$. Tal como se puede ver, destaca de manera muy significativa la proporción que presenta en este caso el área de Ciencias Sociales, seguida a distancia considerable por las de Ingenierías y Salud.

Especialidad: En esta categoría registran 17 titulaciones en total, distribuidas por áreas académicas de la siguiente manera: a) Ciencias Básicas: 1 (5,88\%); b) Ciencias 
Sociales: 3 (17,64\%); c) Salud: 13 (76,47\%). Únicamente estas tres áreas académicas registran titulaciones en la categoría de "especialidad"; al respecto, la de Salud es la que concentra de manera superlativa la mayor proporción de ellas. En la figura 7 se presenta la distribución por categorías de titulación de posgrado de la UCR por áreas académicas.

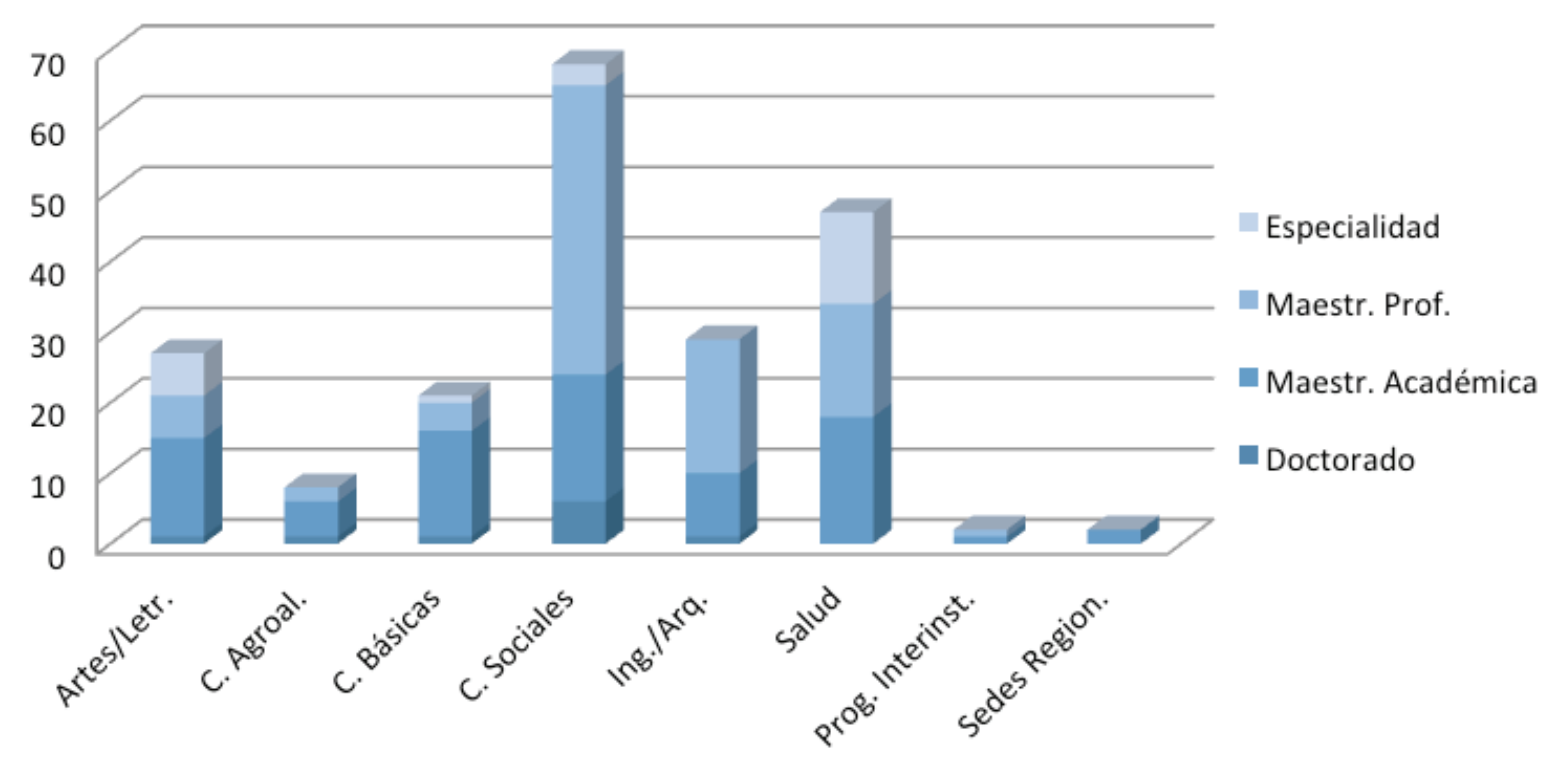

Figura 7. SEP: Distribución de categorías de titulación por áreas académicas. Sistema de Estudios de Posgrado (SEP), Universidad de Costa Rica (2014).

\section{IV.4. Contenidos de internacionalización en los planes de estudios}

Tal como ya se mencionó en la sección de referencialidad teórica, uno de los aspectos que se toman en cuenta a la hora de realizar análisis sobre la internacionalización de la educación superior es el de la incorporación de contenidos de internacionalización en los planes de estudio. En el presente caso, de las 220 carreras de posgrado que aparecen registradas en la página web del SEP, únicamente 6 de ellas presentan algún contenido de internacionalización en los planes de estudios.

$\mathrm{Al}$ respecto, quizá cabría presuponer como probable, que por tratarse los programas de posgrado de una formación especializada - y ya no tanto de desarrollo de bases disciplinares, como es usual en las carreras de grado- no se perciba como de importancia incorporar contenidos de internacionalización en los planes de estudios. Aun así, también sería pertinente decir que, en caso de que existiera esa presuposición, ella no dejaría de representar, en este momento, una cuestión a la que seguramente sería importante prestarle una mayor atención. 


\section{IV.5. Divulgación de información}

\section{Páginas web}

En la actualidad, uno de los aspectos básicos con que deben contar las unidades académicas y las diferentes carreras que se imparten en la universidad es la disposición de páginas web que permitan divulgar información acerca de diversos aspectos: planes de estudio, proyectos de investigación y de extensión o acción social, planta docente, estudiantes, relaciones internacionales (interuniversitarias e interinstitucionales), cooperación internacional, movilidad académica y estudiantil, proyectos docentes y de investigación conjuntos a escala interuniversitaria e internacional, publicaciones.

En tal sentido, es de interés mencionar que de las 220 carreras de posgrado con información registrada en la página Web del SEP, únicamente 28 de ellas $(12,72 \%)$ informan disponer de una página web propia, o bien ubicada en la unidad académica (escuela) a la que esas carreras pertenecen. De las restantes 192 carreras $(87,28 \%)$, toda la información que se ofrece es exclusivamente por medio de la página web del SEP. Es decir, que la divulgación de la información relativa a cada una de esas 192 carreras ha sido asumida por el Decanato del SEP, lo cual significa, por lo tanto, que no ha sido todavía en la actividad de gestión de las propias carreras donde se haya generado el interés y se haya valorado la importancia de contar con un medio para la divulgación vía página web de la información que podría ser relevante dar a conocer.

Un aspecto que también interesa mencionar aquí, en el caso de las carreras que sí indican disponer de una página web propia, es que la organización de la información y los ítems de divulgación que en ellas se presentan son, incluso, aún más discretos o limitados que los que aparecen en el diseño único utilizado por el SEP para divulgar la información de las carreras que no cuentan con su propia página web.

Información sobre el plan de estudios

Asimismo, resulta también importante mencionar que, de las 220 carreras, 23 (10,45\%) no presentan plan de estudios en la información que aparece registrada vía página web. Esta es una situación que puede ser claramente calificada como bastante deficitaria, desde el punto de vista de la gestión de la información académica y de la divulgación que debe hacerse de ella en la universidad.

\section{Lineas de investigación}

En la gráfica siguiente se presenta, por áreas académicas, la cantidad de programas que en la información disponible en página web mencionan las líneas de investigación en las que trabajan y que tienen establecidas como las de su interés principal. Al respecto, se hace una comparación entre la cantidad total de carreras de cada área académica y la cantidad de ellas que mencionan las temáticas de investigación. En la figura 8 se muestra, por áreas académicas, la cantidad de carreras de posgrado que menciona las líneas de investigación que desarrollan. 


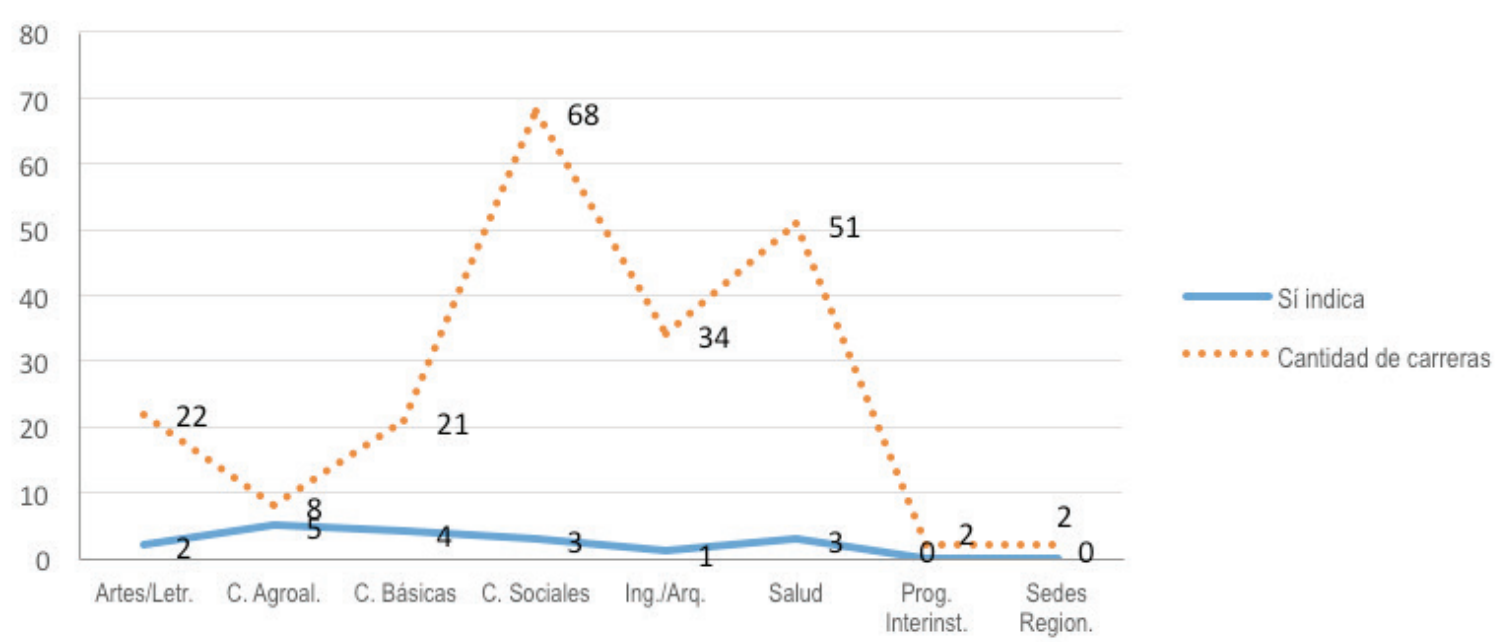

Figura 8. SEP: Cantidad de carreras de posgrado que menciona las líneas de investigación que desarrollan, por áreas académicas. Sistema de Estudios de Posgrado (SEP), Universidad de Costa Rica (2014).

Según lo anterior, del total de las 220 carreras de posgrado registradas en la página web del SEP, únicamente el 8,18\% de ellas da información acerca de las líneas de investigación que desarrollan. Esta pareciera ser una situación a la que habría que prestar atención y dedicación de análisis, sobre todo en los tiempos actuales, cuando el conocimiento y, por consiguiente, la investigación, pasan a ocupar un lugar de primer orden en el ámbito de la formación académica y profesional universitaria.

No solo desde el punto de vista de la internacionalización, sino desde cualquiera otra óptica que se la quiera valorar, es importante dar a conocer la información sobre las líneas de investigación que se desarrollan en las carreras de posgrado, ponerla al alcance de toda clase de actores y del público en general: colegas de otras universidades e instituciones de investigación (nacionales y extranjeras), organismos de cooperación (nacionales, internacionales, multilaterales), instituciones públicas y privadas, organizaciones de la sociedad civil, asociaciones de productores, sector empresarial...

\section{IV.6. Relaciones de cooperación con universidades e instituciones del extranjero, agencias de cooperación, asociaciones y organismos internacionales}

Es importante destacar que de las 220 carreras de posgrado registradas en la página web del SEP, $116(52,72 \%)$ no mencionan las relaciones de cooperación o de otra índole que pudieran tener con universidades e instituciones del extranjero, agencias de cooperación, asociaciones y organismos internacionales.

La cantidad de relaciones internacionales que se indican alcanza un total de 196, distribuidas por áreas académicas de la siguiente manera: a) Artes y Letras: 10 (16); b) Ciencias Agroalimentarias: 1 (6); c) Ciencias Básicas: 24 (20); d) Ciencias Sociales: 127 (70), Ingeniería y Arquitectura: 10 (25), Salud: 18 (92), Programas Interinstitucionales: 6 (2). Las 
cifras entre paréntesis se refieren a la cantidad de carreras de posgrado que existen en cada una de las diferentes áreas académicas. En la figura 9 se muestra por áreas académicas, la distribución porcentual de las relaciones internacionales que mantienen establecidas las carreras de posgrado de la UCR.

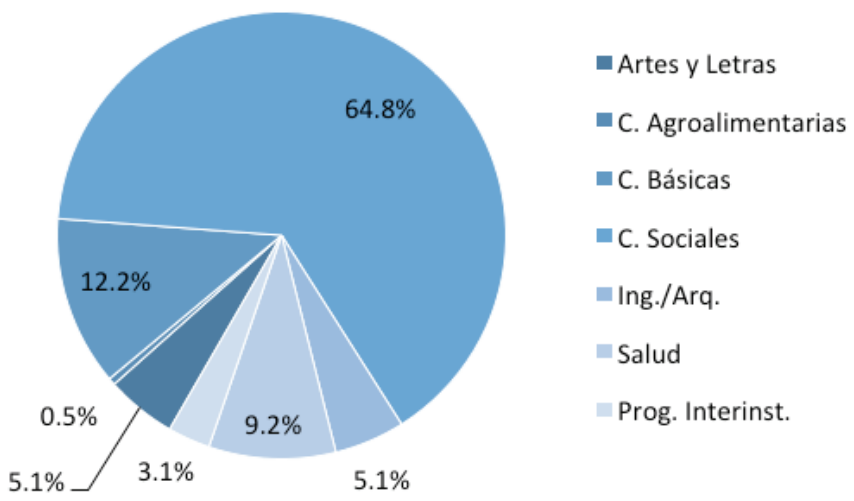

Figura 9. SEP: Distribución de relaciones internacionales de las carreras de posgrado, por áreas académicas. Sistema de Estudios de Posgrado (SEP), Universidad de Costa Rica (2014).

\section{Distribución por países}

Las 196 relaciones internacionales se distribuyen en una totalidad de 25 países, con una alta concentración en 6 de ellos: Alemania, Canadá, España, Estados Unidos, Francia y México. Las restantes 54 relaciones se distribuyen en los demás 19 países, representan una proporción de 27,6\%. Es importante destacar que México es el único país de América Latina que figura entre los 6 países con los que se tiene establecidas una mayor cantidad de relaciones. La figura 10 presenta la distribución porcentual por países, de las relaciones internacionales que informan tener las carreras de posgrado de la UCR.

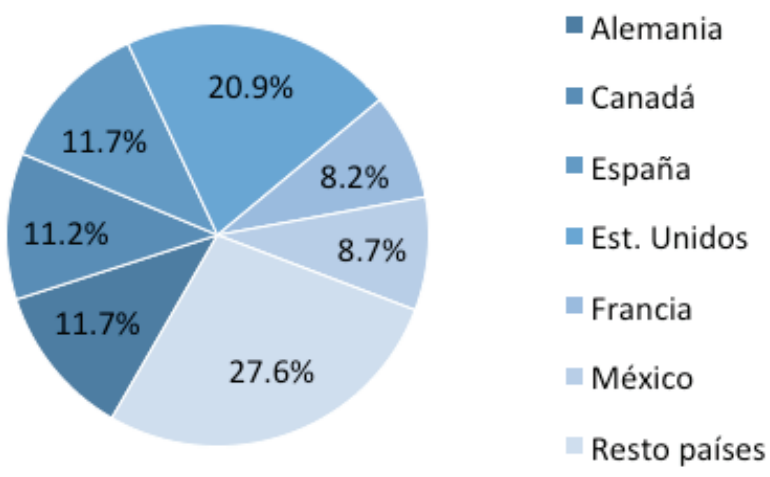

Figura 10. SEP: Distribución de relaciones internacionales de las carreras de posgrado, por países. Sistema de Estudios de Posgrado (SEP), Universidad de Costa Rica (2014). 


\section{Distribución por regiones del mundo}

Respecto de la distribución de las relaciones por regiones del mundo, es importante mencionar que una proporción de 20,1\% corresponde a América Latina, entretanto que un 6,63\% del total corresponde a la subregión de Centroamérica. La figura 11 muestra la distribución porcentual de las relaciones internacionales de las carreras de posgrado, por regiones del mundo.

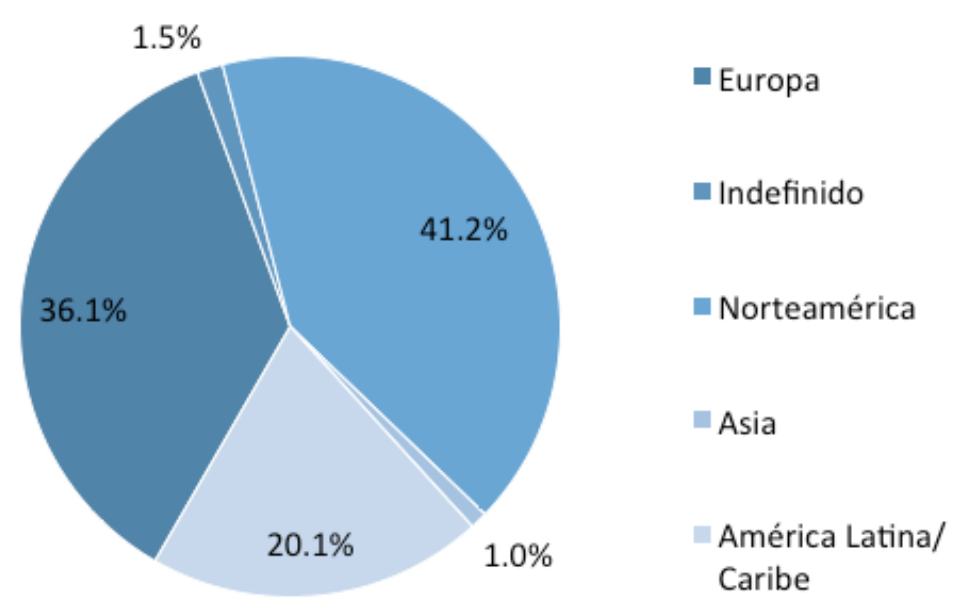

Figura 11. SEP: Distribución de relaciones internacionales de las carreras de posgrado, por regiones del mundo. Sistema de Estudios de Posgrado (SEP), Universidad de Costa Rica (2014).

Tipo de institución con las que se tienen establecidas las relaciones internacionales

Asimismo, de las 196 relaciones internacionales, su distribución en general por tipo de institución es la siguiente: a) universidades: 86 ; b) centros e institutos especializados de investigación: 26; c) otros organismos: 34. En la figura 12 se ofrece la distribución porcentual de las relaciones internacionales de las carreras de posgrado, por tipo de instituciones.

Las universidades con las que se menciona tener la mayor cantidad de relaciones establecidas son la Universidad Nacional Autónoma de México (UNAM) y la Universidad Laval (Canadá), con una cantidad de 9 y 8 relaciones cada una de ellas, respectivamente. A estas 2 universidades les siguen, con un registro de 3 relaciones cada una, la Universidad Nacional Autónoma de Nicaragua, Universidad de Barcelona, Universidad Castilla La Mancha, Universidad de Panamá, Universidad de Dresden (Alemania), Universidad de Minnesota, Universidad de New Orleans, Universidad de Stuttgart (Alemania) y Universidad de Tubinga (Alemania).

De las 86 universidades, 62 de ellas no registran tener un convenio institucional vigente con la Universidad de Costa Rica, de conformidad con la información que se ofrece al respecto en la página web de la Oficina de Asuntos Internacionales y Cooperación Externa (OAICE, Oficina de Asuntos Internacionales y Cooperación Externa, 2014, s. p.). 


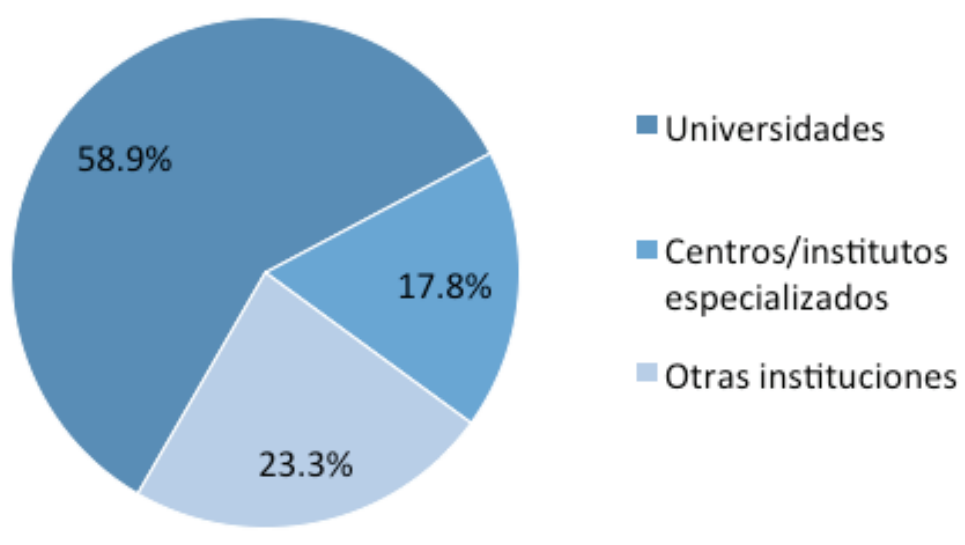

Figura 12. SEP: Distribución de relaciones internacionales de las carreras de posgrado, por tipo de instituciones. Sistema de Estudios de Posgrado (SEP), Universidad de Costa Rica (2014).

\section{IV.7. Dominio de una segunda lengua como requisito de ingreso a los programas de posgrado}

Se hizo una revisión respecto del dominio de una segunda lengua (o lengua extranjera), como requisito para ingresar a las carreras de posgrado. En total, son 85 las carreras que mencionan tener establecido dicho requisito; es decir, el 38,63\% del total de las carreras de posgrado de la UCR. De esas 85 carreras, en el 96,47\% de los casos, el requisito consiste en demostrar dominio instrumental o competencia de lectura en alguna segunda lengua. En la figura 13 se presentan los resultados generales obtenidos, distribuidos por áreas académicas:

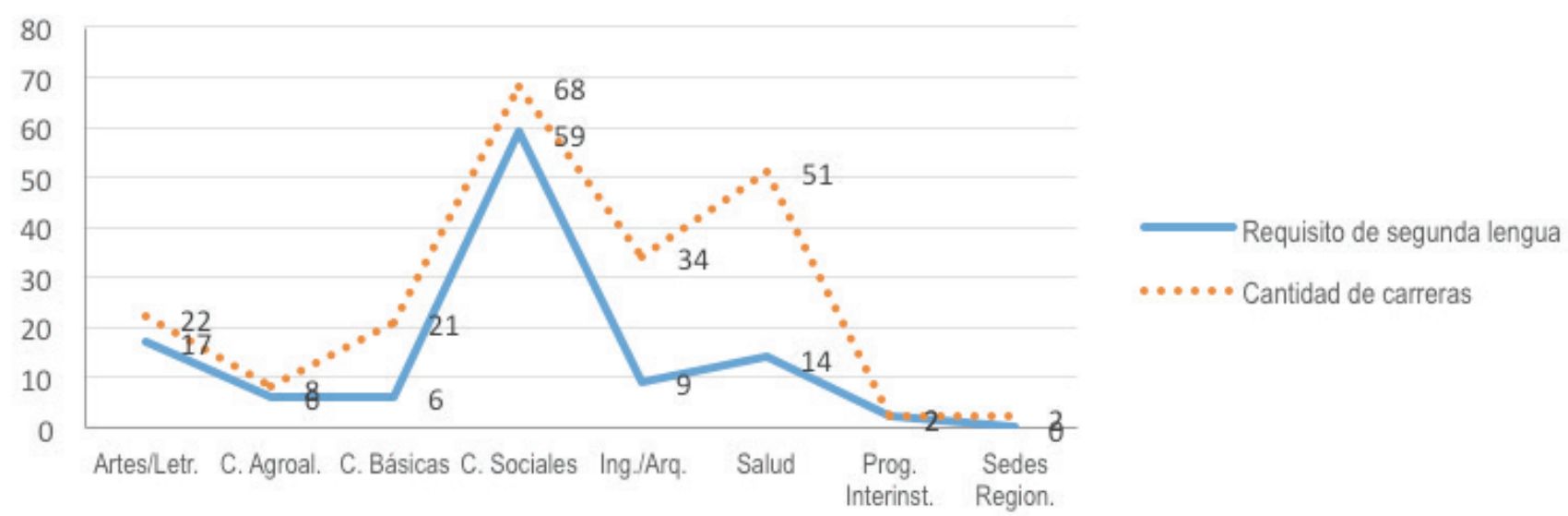

Figura 13. SEP: Cantidad de carreras de posgrado que solicitan como requisito de ingreso el dominio de una segunda lengua, por áreas académicas. Sistema de Estudios de Posgrado (SEP), Universidad de Costa Rica (2014). 
El dominio de una segunda lengua como requisito para ingresar a las carreras de posgrado de la UCR, según la información obtenida vía página web, no parece ser de mayor obligatoriedad y se circunscribe a un dominio instrumental, o bien, a una demostración de capacidad de lectura. En la gráfica anterior se puede observar que el requisito es importante para las áreas académicas de Artes y Letras y de Ciencias Sociales, pero no tanto para las de Salud y de Ingeniería y Arquitectura.

\section{Consideraciones finales}

En la universidad, la internacionalización del posgrado puede asumir, en general, una de dos distintas finalidades, lo mismo que también puede suceder en las carreras de grado, la investigación y otras diversas actividades académicas. Una de esas finalidades consiste en posicionar la oferta de servicios de formación profesional en el mercado internacional de las titulaciones universitarias, bien sea por medio de la oferta de dichos servicios en el propio país, o bien instalándola en otro u otros países o, también, desarrollándola a través de programas a distancia virtuales o en línea.

La otra finalidad, en sentido distinto a la anterior, consiste en desarrollar relaciones interinstitucionales colaborativas y de intercambio recíproco, en procura de mejorar y fortalecer las propias condiciones que favorezcan el logro de una formación de alto nivel de excelencia, que respeten y resguarden las propias identidades académicas, institucionales y culturales, así como centradas en el principio de que el mayor valor de la formación universitaria y de los conocimientos reside en las significaciones que estos adquieren en sus propios anclajes en territorialidades socio históricas, institucionales y culturales específicas.

Esta segunda finalidad, valga subrayarlo, hace énfasis en relevar la importancia de preservar la condición de la formación académica y profesional y del conocimiento en su naturaleza de bienes públicos, que deben estar al servicio de la sociedad y por medio de los cuales la universidad contribuye con el fortalecimiento de la institucionalidad democrática, la aportación de acciones y propuestas proactivas para atender y resolver las situaciones de la injusticia social y la inequidad; un quehacer académico centrado y comprometido con un desarrollo nacional integral e incluyente, garante de asegurar las condiciones que conduzcan al logro del bienestar común, con una clara conciencia de los principios de la independencia, la soberanía nacional y el respeto por la diversidad étnica y cultural del país.

En la bibliografía especializada y también por parte de diversos organismos (a escala nacional, por ejemplo, el CONARE en Costa Rica, e internacional, como la UNESCO), la internacionalización de la educación superior es valorada como importante, en la medida en que, desde una perspectiva de relaciones interinstitucionales de cooperación solidaria y de beneficio recíproco, puede favorecer la movilidad y el intercambio internacional de docentes y estudiantes, el desarrollo conjunto de acciones y proyectos de formación y de investigación, el aprovechamiento de las plataformas y los diversos recursos de la comunicación virtual para, en su caso, compartir cursos, impartir conferencias, desarrollar lecciones a distancia, proporcionar asesorías y participar en la dirección y tutoría de los proyectos de investigación de la población estudiantil. 
Las internacionalización puede no solo contribuir a enriquecer las visiones de mundo que se tienen, sino que, de igual manera, puede aportar también elementos para valorar mejor la propia cultura local y nacional, a la vez que contribuye a que las personas desarrollen interés por conocer otras experiencias institucionales, epistemológicas, metodológicas y axiológicas de acceder al estudio y al abordaje propositivo de los problemas inherentes al campo específico disciplinar en el que ellas están llevando a cabo sus estudios.

En el contexto de los planes de estudio, asimismo, la internacionalización del currículo contribuye a una formación en la que se llega a desarrollar la conciencia de que la actual condición humana se encuentra caracterizada por la interdependencia planetaria, por la inter y la multiculturalidad, la transnacionalidad de los diversos problemas que hoy afectan y preocupan a la humanidad en su conjunto: crisis económicas, guerra en riesgo de mundializarse, desastres ambientales, pobreza, hambre, exclusión e incremento de las desigualdades sociales, enfermedades, intoxicación y agotamiento de los bienes naturales imprescindibles para la preservación de la vida en el planeta...

En su caso, en el nivel del posgrado, parece importante plantearse ahora, en los planes de estudio, una discusión en detalle en torno a los contenidos incluidos en ellos, así como en relación con la forma de articular dichos planes con la investigación. A tal efecto, cabe considerar la posible necesidad de definir las propias políticas en las que pueda quedar enmarcada la investigación, en el sentido de relevar los propios avances nacionales en materia de investigación y de desarrollo de saberes acumulados en la experiencia práctica.

De lo que se trataría es de adecuar los planes de estudio en razón de la visión construida en torno a las necesidades cruciales y estructurales del país en materia de desarrollo nacional y de incorporación de formación profesional, y de iniciativas de formación y de investigación que contribuyan al logro de un desarrollo nacional diverso, autóctono, con una apropiada generación y adecuación del conocimiento científico y tecnológico,

Asimismo, parece apropiado proponer que en carreras de posgrado cuya planta académica cuenta con poca experiencia de relacionamiento internacional, ya sea en el campo de la investigación o en el de la movilidad académica, la internacionalización puede propiciar iniciativas de mejora, por medio de la apertura de espacios para que su personal académico fortalezca sus experiencias y perfiles de formación académica por medio de la realización de estudios en las universidades con las cuales se han establecido relaciones de colaboración e intercambio.

El país requiere no solo contar con una planta académica y profesional formada al más alto nivel, sino que, además, es imprescindible que eso sea así en todas las diferentes áreas del conocimiento. No se debiera privilegiar determinadas áreas ni determinadas especialidades, en razón, por ejemplo, de favorecer condiciones de capacidades locales y de mercado de trabajo para satisfacer las demandas de competencias profesionales, científicas y tecnológicas que plantean las empresas transnacionales de la inversión extranjera directa (IED).

En lo que concierne a los resultados de la indagación exploratoria presentados en este artículo, estos señalan una existencia todavía bastante baja o nula de divulgación de información acerca de las iniciativas y acciones de internacionalización que se hayan podido emprender, o que se puedan estar llevando a cabo, por parte de los programas y las carreras 
de posgrado de la UCR. La información disponible en página web sugiere que el tema de la internacionalización no ha sido todavía considerado como de importancia por parte de las direcciones de los programas y las carreras de posgrado.

Desde luego, lo anterior tampoco significaría que la internacionalización no esté presente en las actividades académicas y de gestión del posgrado. Eso parece ser prácticamente imposible. Con todo, sí es necesario tener en cuenta que, al menos desde hace alrededor de dos décadas y media, la internacionalización ha pasado a requerir de organizar acciones programáticas en la universidad, las cuales involucran su incorporación en la política institucional, los planes de estudio, la investigación, el intercambio académico y, también, los criterios e indicadores con base en los cuales se diseñan los medios para la divulgación de información, entre ellos, de manera especial, las páginas web, que han pasado a ser ahora uno de los recursos de divulgación más importantes e imprescindibles.

De momento, la exploración preliminar aquí presentada deja pendiente conocer cuáles son las valoraciones que puedan existir en la comunidad académica y en las instancias de gestión de los programas y las carreras de posgrado de la UCR, en torno a las diversas cuestiones relacionadas con la internacionalización de la educación superior en ese nivel específico de la formación y del quehacer académico universitario. Este pendiente formará parte central de una segunda etapa de investigación.

\section{Referencias}

Altbach, P. G. y J. Knight. (2006). Visión panorámica de la internacionalización en la educación superior: Motivaciones y realidades. Perfiles Educativos Mexicanos, 28(112), 13-39. Recuperado de http://www.scielo.org.mx/pdf/peredu/v28n112/n112a2.pdf

Altbach, P. (2009). Funciones complejas de las universidades en la era de la globalización. En: Global University Network for Innovation (Ed.), La educación superior en tiempos de cambio. Nuevas dinámicas para la responsabilidad social (pp. 31-36). Madrid: Global University Network for Innovation/Ediciones Mundi-Prensa. Recuperado de http:// upcommons.upc.edu/bitstream/handle/2099/9540/ESM Sin 09.pdf;jsessionid=E1D77A 36E073AF6D1A3007BF9A099032? sequence $=6$

Bauman, Z. (2001). La globalización. Consecuencias humanas. Ciudad de México: Fondo de Cultura Económica.

Beelen, J. (2011). La internacionalización en casa en una perspectiva global: Un estudio crítico del Informe del 3. ${ }^{\text {er }}$ Estudio Global de la AIU. Revista de Universidad y Sociedad del Conocimiento, 8(2), 85-100. doi: http://dx.doi.org/10.7238/rusc.v8i2.1094

Bennani, A. (2009). La contribución de la educación superior a la convivencia multicultural: Retos presentes y futuros. En Global University Network for Innovation (Ed.), La educación superior en tiempos de cambio. Nuevas dinámicas para la responsabilidad 
social (pp. 58-60). Madrid: Global University Network for Innovation/Ediciones MundiPrensa. Recuperado de http://upcommons.upc.edu/bitstream/handle/2099/9540/ESM Sin 09.pdf;jsessionid=E1D77A36E073AF6D1A3007BF9A099032? sequence $=6$

Conferencia Mundial sobre la Educación Superior. (1998). La educación superior en el siglo XXI. Visión y acción. París: División de la Educación Superior/UNESCO.

Conferencia Mundial sobre la Educación Superior. (2009). Comunicado (8 de julio de 2009). París: Unesco. Recuperado de http://www.unesco.org/education/WCHE2009/comunicado es.pdf

Consejo Nacional de Rectores. (2011). Plan Nacional de la Educación Superior Universitaria Estatal 2011/2015. Recuperado de http://www.tec.ac.cr/d01/CI/Documentos\%20Varios/ CONARE PLANES 20112015 VERSION EN CONSULTA\%2018\%20agost.pdf

Consejo Nacional de Rectores. (s. f.). Información estadística. Recuperado de http://www. conare.ac.cr/index.php/servicios/informacion-estadistica.html

Delanty, G. (2009). La universidad y la ciudadanía cosmopolita. En Global University Network for Innovation (Ed.), La educación superior en tiempos de cambio. Nuevas dinámicas para la responsabilidad social (pp. 60-62). Madrid: Global University Network for Innovation/Ediciones Mundi-Prensa.

Delgado-Márquez, B., Torres-Hurtado, N. y Bondar, Y. (2011). La internacionalización de la enseñanza superior: Investigación teórica y empírica sobre su influencia en las clasificaciones de las instituciones universitarias. Revista de Universidad y Sociedad del Conocimiento, 8(2), 101-122. Doi: http://dx.doi.org/10.7238/rusc.v8i2.1069

de Wit, H. (2011). Globalización e internacionalización de la educación superior. Revista de Universidad y Sociedad del Conocimiento, 8(2), 77-84. Recuperado de http://rusc.uoc.edu/ index.php/rusc/article/view/v8n2-globalizacion-e-internacionalizacion-de-la-educacionsuperior/v8n2-globalizacion-e-internacionalizacion-de-la-educacion-superior

Días, J. (2008). Cambios y reformas en la educación superior. En C. Tünnermann Bernheim, (Ed.), La educación superior en América Latina y el Caribe: Diez años después de la Conferencia Mundial de 1998 (pp. 95-140). Sello Editorial Javeriano/IESALC: Bogotá.

Días, M. A. (2008). La internacionalización y la cooperación universitaria en la sociedad del conocimiento. En C. Tünnermann, (Ed.). (2008). La educación superior en América Latina y el Caribe: diez años después de la Conferencia Mundial de 1998. (pp. 313-366) Sello Editorial Javeriano/IESALC: Bogotá. 
González, E. (2010). El estado del arte de los posgrados e investigación latinoamericana y caribeña. Importancia de la CRES 2008, la CMES 2009 y el ENLACES. En L. Luchilo (Comp.), Formación de posgrado en América Latina: Políticas de apoyo, resultados e impacto (33-50). Eudeba: Buenos Aires. Recuperado de http://www.oei.es/salactsi/ formacion de postgrado.PDF

Guido, E. y A. Guzmán. (2012). Criterios para internacionalizar el currículum universitario. Revista Electrónica Actualidades Investigativas en Educación, 12(1), 1-25. Recuperado de http://www.redalyc.org/pdf/447/44723363002.pdf

Knight, J. (s. f.). Internacionalización de la educación superior. Recuperado de http://www. ugto.mx/internacional/images/pdf/4a.pdf

Knight, J. (2005). Un modelo de internacionalización: Respuesta a nuevas realidades y retos. En H. de Wit, C. Jaramillo, J. Gacel-Avila y J. Khight. (Eds.), Educación superior en América Latina. La dimensión internacional (pp. 1-38). Bogotá: Banco Mundial/Mayol Ediciones. Recuperado de http://www.oecdbookshop.org/get-it.php?REF=5L9HXS561J3 8\&TYPE=browse

Knight, J. (2011). Dudas y conflictos en torno a los programas de grado doble. Revista de Universidad y Sociedad del Conocimiento, 8(2), 135-151. doi: http://dx.doi.org/10.7238/rusc.v8i2.1067

Moja, T. (2009). Desafíos institucionales y sus implicaciones en las instituciones de educación superior (IES): Transformación, misión y visión para el siglo XXI. En Global University Network for Innovation (Ed.), La educación superior en tiempos de cambio. Nuevas dinámicas para la responsabilidad social (pp. 41-44). Madrid: Global University Network for Innovation/Ediciones Mundi-Prensa.

Muñoz, L. (2014). Pendientes en la agenda de investigación en Costa Rica sobre internacionalización de la educación superior. Observatorio de la Educación Nacional y Regional/Instituto de Investigación en Educación (Universidad de Costa Rica). Recuperado de http://observatorio.inie.ucr.ac.cr/attachments/article/33/Pendientes\%20agenda\%20 investigaci\%C3\%B3n\%20internacionalizaci\%C3\%B3n\%20educaci\%C3\%B3n\%20 superior $\% 20 I N I E \% 20$ para $\% 20$ subir.pdf

Nayyar, D. (2009). La globalización y los mercados: Implicaciones para la educación superior. En Global University Network for Innovation (Ed.), La educación superior en tiempos de cambio. Nuevas dinámicas para la responsabilidad social (pp. 27-30). Madrid: Global University Network for Innovation/Ediciones Mundi-Prensa. 
Ocampo-Hernández, B. (2014). RIFED invita a internacionalizar la docencia. Portal Web de la Universidad de Costa Rica. Recuperado de http://www.ucr.ac.cr/noticias/2014/08/31/ rifed-invita-a-internacionalizar-la-docencia.html

Oficina de Asuntos Internacionales y Cooperación Externa. (2014). Convenios firmados por la Universidad de Costa Rica con Instituciones del Exterior. Recuperado de http://www.oaice. ucr.ac.cr/ oaice/index.php?option=com content\&view=article\&id=19\&Itemid=3\&lang=es

Oficina de Planificación Universitaria (OPLAU). (2012). Universidad de Costa Rica Panorama cuantititativo universitario. Recuperado de http://www.oplau.ucr.ac.cr/phocadownload/ panorama/panorama2012/docencia 2012.pdf

Pérez, M. (s. f.). Sistema de Estudios de Posgrado: Un sello de calidad, pertinencia e impacto. Recuperado de http://www.sep.ucr.ac.cr/sep/historia.html

Programa Estado de la Nación y Desarrollo Humano Sostenible. (2013). IV Informe Estado de la Educación (Cap. 4). Recuperado de http://www.estadonacion.or.cr/files/biblioteca virtual/educacion/004/9-Cap-4.pdf

Proyecto Estrategia Siglo XXI. (2006). Visión de la ciencia y la tecnología en Costa Rica: Una construcción colectiva (Vol. II). San José de Costa Rica: Fundación Costa Rica Estados Unidos de América para la Cooperación. Recuperado de http://www.estrategia. cr/content/images/pdfs/tomo2.pdf

Torres-Santomé, Jurjo. (2000). Globalización e interdisciplinariedad: El currículum integrado. Madrid: Ediciones Morata. 